\title{
Endoscopic ultrasound-guided transhepatic biliary drainage in altered anatomy: a two-step approach
}

Endoscopic ultrasound (EUS)-guided biliary drainage has been used for more than a decade as an alternative to percutaneous drainage. It offers a minimally invasive option for patients in whom conventional endoscopic retrograde cholangiopancreatography (ERCP) is unfeasible.

A 45-year-old woman with a history of cholecystectomy for cholecystitis, complicated by common bile duct transection with a subsequent Roux-en-Y hepaticojejunostomy was admitted with recurrent cholangitis. A previous attempt at balloon enteroscopy-assisted ERCP had failed and therefore EUS-guided biliary drainage was performed.

The echoendoscope was used to identify the left intrahepatic duct (LIHD) and a 19-gauge needle was used to access the duct. Cholangiogram showed a dilated LIHD with an anastomotic stricture ( $\bullet$ Fig.1a, $\bullet$ Video 1). A guidewire was advanced into the LIHD under fluoroscopic guidance. Multiple attempts to cross the stricture with the guidewire were unsuccessful. A plastic double-pigtail hepaticogastrostomy stent was placed $(\bullet$ Fig. 1 b, $\bullet$ Video 1 ) and the patient was discharged home.
On follow-up endoscopy 2 months later, the guidewire was advanced across the anastomotic stricture via manipulation of a swing-tip catheter. Dilation of the stricture was performed and a transanastomotic hepaticogastrostomy stent was placed ( Fig.1c, $\bullet$ Video 1). At 1-year followup, the patient had experienced no further episodes of cholangitis.

This case highlights a two-step antegrade approach to treat recurrent cholangitis and an anastomotic stricture in a patient with surgically altered anatomy [1]. EUSguided biliary drainage constitutes the least invasive approach in patients with surgically altered anatomy $[2,3]$.

\section{Endoscopy_UCTN_Code_TTT_1AS_2AD}

Competing interests: Michel Kahaleh MD: has received grant support from Boston Scientific, Fujinon, EMcison, Xlumena Inc., W.L. Gore, MaunaKea, Apollo Endosurgery, Cook Endoscopy, ASPIRE Bariatrics, GI Dynamics, NinePoint Medical, Merit Medical, Olympus and MI Tech. He is a consultant for Boston Scientific, Xlumena Inc., Concordia Laboratories Inc, ABBvie, and MaunaKea Tech.
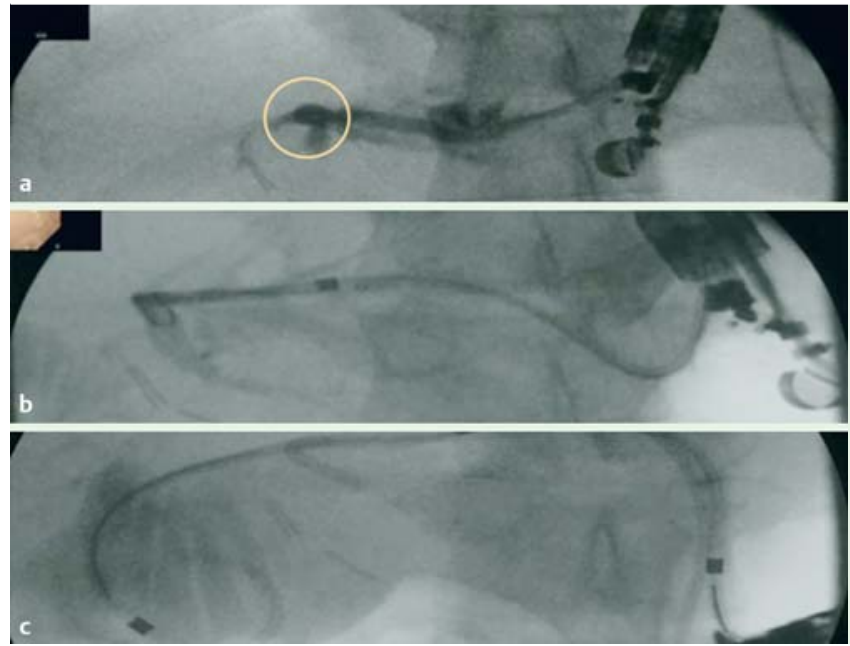

Fig. 1 Three steps for successful treatment of cholangitis and anastomotic stricture. a Cholangiogram showing anastomotic duct stricture (circle). b Deployment of the hepaticogastrostomy stent. c Follow-up jejunohepaticogastrostomy stent placement across the anastomotic stricture.

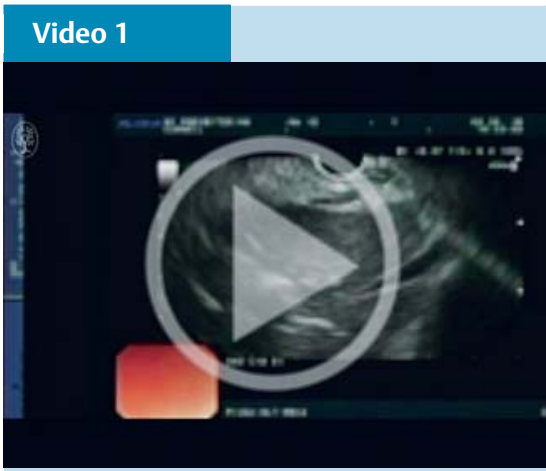

Two steps for successful treatment of cholangitis and anastomotic stricture.

\section{Aleksey Novikov, Nikhil A. Kumta, Benjamin Samstein, Michel Kahaleh}

Division of Gastroenterology and Hepatology, Weil Cornell Medical College, Cornell University New York, New York, United States

\section{References}

1 Iwashita T, Doi S, Yasuda I. Endoscopic ultrasound-guided biliary drainage: a review. Clin J Gastroenterol 2014; 7: 94-102

2 Siripun A, Sripongpun P, Ovartlarnporn B. Endoscopic ultrasound-guided biliary intervention in patients with surgically altered anatomy. World J Gastrointest Endosc 2015; 7: 283-289

3 Artifon EL, Aparicio D, Paione JB et al. Biliary drainage in patients with unresectable, malignant obstruction where ERCP fails. J Clin Gastroenterol 2012; 46: 768 -774

\section{Bibliography}

Dol http://dx.doi.org/

10.1055/s-0042-113598

Endoscopy 2016; 48: E287

(c) Georg Thieme Verlag KG

Stuttgart · New York

ISSN 0013-726X

\section{Corresponding author}

\section{Michel Kahaleh, MD, FASGE}

Division of Gastroenterology and Hepatology Weill Cornell Medical College

New York, NY 10021

USA

Fax: +1-646-962-0110

mkahaleh@gmail.com 